\title{
A Teleseismic Study of the 2002 Denali Fault, Alaska, Earthquake and Implications for Rapid Strong-Motion Estimation
}

\author{
Chen Ji, ${ }^{\text {a) }}$ Don V. Helmberger, ${ }^{\text {a) }}$ and David J. Wald, ${ }^{\text {b) }}$ M.EERI
}

Slip histories for the 2002 M7.9 Denali fault, Alaska, earthquake are derived rapidly from global teleseismic waveform data. In phases, three models improve matching waveform data and recovery of rupture details. In the first model (Phase I), analogous to an automated solution, a simple fault plane is fixed based on the preliminary Harvard Centroid Moment Tensor mechanism and the epicenter provided by the Preliminary Determination of Epicenters. This model is then updated (Phase II) by implementing a more realistic fault geometry inferred from Digital Elevation Model topography and further (Phase III) by using the calibrated $\mathrm{P}$-wave and $\mathrm{SH}$-wave arrival times derived from modeling of the nearby 2002 M6.7 Nenana Mountain earthquake. These models are used to predict the peak ground velocity and the shaking intensity field in the fault vicinity. The procedure to estimate local strong motion could be automated and used for global real-time earthquake shaking and damage assessment. [DOI: 10.1193/1.1778388]

\section{INTRODUCTION}

The ground shaking produced by large earthquakes, such as the recent Izmit, Turkey, and Chi-Chi, Taiwan, events, is one of the greatest catastrophic natural hazards on earth. When such tragedies occur, quick estimates of ground shaking are useful for local governments to evaluate the damage and to allocate their resources accordingly. The ShakeMap method developed under the TriNet project (Wald et al. 1999a, b) provides a tool to obtain such information using observed ground-motion time histories combined with estimates from suitable attenuation relationships. However, it requires a dense distribution of strong-motion stations which are reporting in real time, and which are only available in a limited number of urban areas such as the Los Angeles basin, the San Francisco Bay area, Seattle, Salt Lake City, and parts of Japan and Taiwan. In most seismically active regions, there is no such network, or the station density is insufficient to provide optimal results. Because such networks are costly, we expect few improvements in the near future, particularly for under-developed countries where the earthquake hazard can be extreme.

Although future rapidly derived earthquake information may include satellite-based static measurements (e.g., Interferometric Synthetic Aperture Radar, InSAR), we cur-

\footnotetext{
a) Seismological Laboratory, California Institute of Technology, Pasadena, California

b) United States Geological Survey, Denver, Colorado
}

617 
rently rely entirely on teleseismic observations. For instance, during the first day after a major earthquake, the teleseismic data of the global IRIS (Incorporated Research Institutions for Seismology) network is available online. Recent developments in inverse methodologies and the deployment of modern broadband instruments make it possible to construct a rough slip history with only a teleseismic dataset. Such a model can then be used to predict the ground shaking in the near-fault region, and to provide the basis for gauging the overall impact of the earthquake (e.g., Dreger and Kaverina 2000). In this analysis, the estimates can be validated against the observations when these become available, and against more detailed models, which will include near-source strong motion, geodetic positioning system (GPS) methods, and surface offset measurements. The recent 2002 M7.9* Denali fault earthquake created an ideal example to address these issues and to examine the accuracy of this procedure using teleseismic data alone. The goal of this paper is not to present a well-constrained model of this earthquake. Instead, we want to show the potential for quick predictions of strong motion and fault breakage.

The 2002 M6.7 Nenana Mountain and M7.9 Denali fault earthquake sequence occurred on a major right-lateral strike-slip fault system in central Alaska in response to the oblique collision between the Yakutat terrane and the North American continental margin (Lahr and Plafker 1980); see Figure 1. The slip rate of the Denali fault is 1 to 2 $\mathrm{cm} / \mathrm{yr}$ during the Holocene (Page et al. 1995). However, west of about $146^{\circ} \mathrm{W}$ longitude, recent slip on the Denali fault diminishes; east of about $143^{\circ} \mathrm{W}$ longitude, most of the recent slip is on the Totschunda branch rather than the extension of the Denali fault trace (Page et al. 1995). On October 23, 2002, the M6.7 Nenana Mountain earthquake occurred on the Denali fault (Figure 1). Eleven days later, the M7.9 Denali fault earthquake initiated $22 \mathrm{~km}$ to $25 \mathrm{~km}$ east of the earlier event with a thrust focal mechanism, but then ruptured toward the southeast in a mainly strike-slip sense and created a surface break 218 to $220 \mathrm{~km}$ long before finally jumping onto the Totschunda fault. This event is the largest strike-slip earthquake in the United States since the 1906 San Francisco earthquake.

We started working one day after the Denali fault earthquake using teleseismic body waves downloaded from the IRIS data center. Although over 200 broadband stations worldwide send data to the IRIS data center in near real time and provide good azimuthal coverage, to recover an accurate seismic slip history requires local data coverage and detailed fault geometry. Neither was available during the first day. Instead of waiting for this information, we started with several simple assumptions, and then progressively improved upon them with geological and seismological constraints on the fault system. This paper addresses these issues and demonstrates the ability of such an approach to predict near-field observations.

\section{FINITE-FAULT INVERSION METHOD}

The finite-fault inverse method has been used by many researchers, (e.g., Hartzell and Heaton 1983). Basically, the seismic and static response of a finite-size fault plane can be represented as a summation of contributions from the subfaults (Ji et al. 2002a),

\footnotetext{
* All magnitudes in this paper, unless otherwise indicated, are moment magnitudes, M.
} 


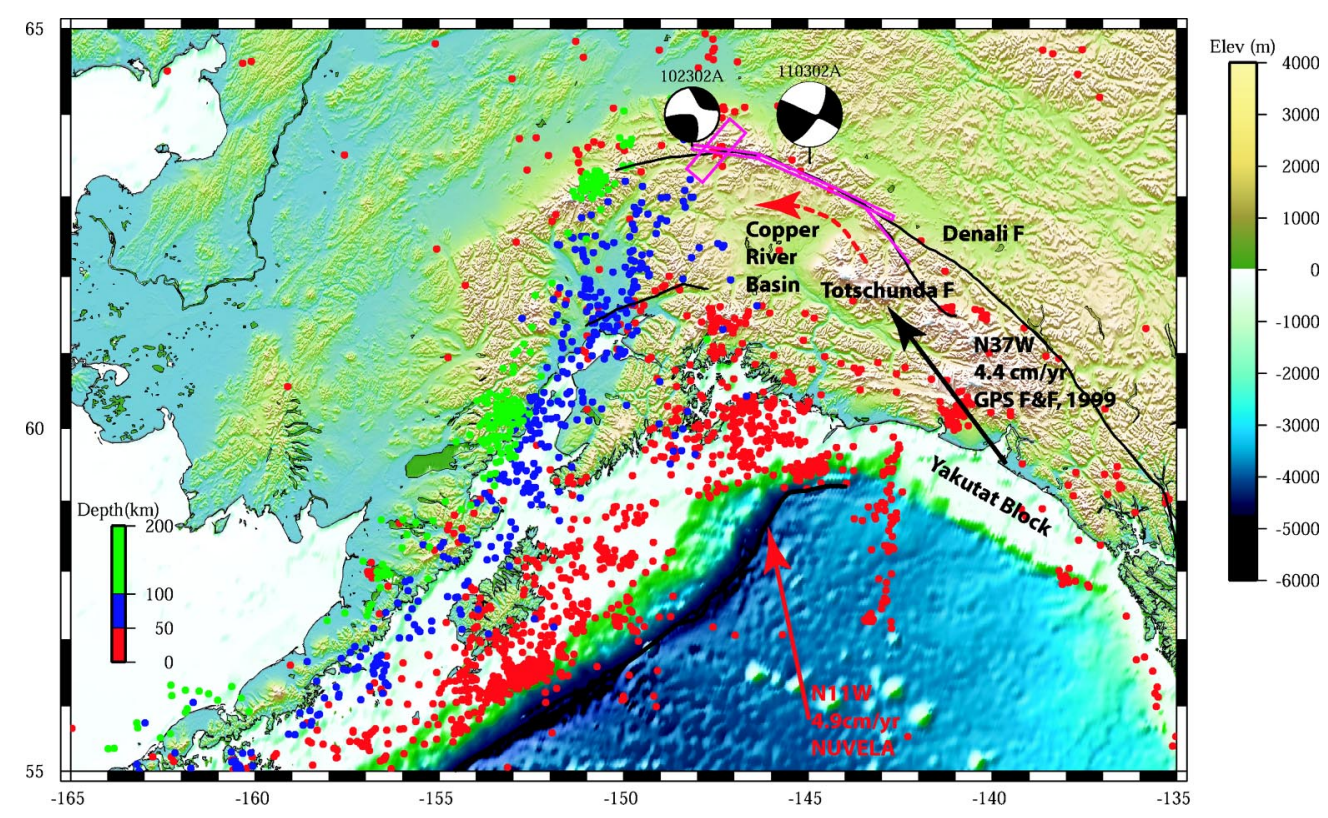

Figure 1. Tectonic framework. Earthquakes within the relocated ISC catalog (Engdahl et al. 1998) are plotted with filled circles to illustrate the shape of the subducted Pacific plate. Their hypocenter depths are indicated by shades. Thin lines show the Denali and Totschunda faults on the base map of the Alaskan topography. Two focal mechanisms indicate the Harvard CMT solutions for the 2002 Nenana Mountain and Denali fault earthquakes; boxes show the surface projections of the Phase III model discussed later. Both events occurred east of the subducted plate. The white vector shows the convergent velocity relative to the North American plate based on NUVELA (Demets et al. 1994). The black arrow indicates the motion direction of the Yakutat block relative to the same reference (Fletcher and Freymueller 1999).

$$
u(t)=\sum_{j=1}^{n} \sum_{k=1}^{n} D_{j k}\left[\cos \left(\lambda_{j k}\right) Y_{j k}^{1}\left(V_{j k}, t\right)+\sin \left(\lambda_{j k}\right) Y_{j k}^{2}\left(V_{j k}, t\right)\right] * S_{j k}(t)
$$

where $D_{j k}$ is the slip amplitude (offset); $\lambda_{j k}$ is the rake angle; $S_{j k}$ is the rise time function; $V_{j k}$ is the average rupture velocity between the hypocenter and subfault $j k$; and $Y_{j k}^{i}$ $\left(V_{j k}, t\right)$ are subfault Green's functions. We further represent a subfault Green's function as a summation of many point sources to take the directivity inside a subfault into account (Ji et al. 2002a). With this approach, we can invert for the slip history on the fault surface by fitting the observed seismic waveforms; after we construct a slip model, the ground motion in the near-fault region can be predicted with the above relationship.

While the finite fault inversion is straightforward in theory, accurate recovery of the slip history with just the teleseismic data is, in fact, a challenging problem. The success of the inversion requires accurate Green's functions; but, for computational efficiency, the Green's functions in most finite-fault inversions are calculated using a onedimensional (1D) earth structure. Even though the waveforms of teleseismic body 
Table 1. Moment tensor solutions of the 2002 Denali fault earthquake

\begin{tabular}{|c|c|c|c|c|c|c|c|c|c|c|}
\hline & \multicolumn{6}{|c|}{ Moment Tensor $\left(10^{20} \mathrm{Nm}\right)$} & \multicolumn{4}{|c|}{ Best Double Couples } \\
\hline & $\mathrm{M}_{\mathrm{rr}}$ & $\mathrm{M}_{\mathrm{pp}}$ & $\mathrm{M}_{\mathrm{tt}}$ & $\mathrm{M}_{\mathrm{rp}}$ & $\mathrm{M}_{\mathrm{rt}}$ & $\mathrm{M}_{\mathrm{pt}}$ & $\theta(\mathrm{deg})$ & $\delta(\operatorname{deg})$ & $\lambda(\mathrm{deg})$ & $\begin{array}{c}\mathrm{M}_{0} \\
10^{20} \mathrm{Nm}\end{array}$ \\
\hline $\begin{array}{r}\text { Harvard CMT } \\
\text { (Preliminary) }\end{array}$ & 0.47 & -6.24 & 5.77 & -2.15 & 1.66 & -3.86 & $298 / 29$ & $86 / 69$ & $159 / 4$ & 7.64 \\
\hline $\begin{array}{l}\text { Harvard CMT } \\
\text { (Final) }\end{array}$ & 0.51 & -6.04 & 5.53 & 0.18 & 2.62 & -3.94 & $296 / 29$ & $71 / 82$ & $171 / 19$ & 7.48 \\
\hline $\begin{array}{c}\mathrm{CMT}^{*} \\
\text { (Phase III) }\end{array}$ & $\begin{array}{l}0.56 \\
/ 0.52\end{array}$ & $\begin{array}{l}-7.38 \\
/-6.46\end{array}$ & $\begin{array}{l}6.82 \\
15.94\end{array}$ & $\begin{array}{c}0.69 \\
/ 0.66\end{array}$ & $\begin{array}{l}1.25 \\
/ 1.10\end{array}$ & $\begin{array}{l}-5.75 \\
/-5.06\end{array}$ & $\begin{array}{c}296 / 26 \\
(295 / 25)\end{array}$ & $\begin{array}{c}81 / 90 \\
(81 / 89)\end{array}$ & $\begin{array}{c}180 / 9 \\
(180 / 9)\end{array}$ & $\begin{array}{c}9.24 \\
(8.10)\end{array}$ \\
\hline
\end{tabular}

* The two seismic moment tensor solutions based on the finite fault model of Phase III are calculated with rigidity derived from Crust2.0 (Laske et al. 2001, upper) or continental PREM (lower) models. Strike, dip, and rake angles of the best double-couple planes are $\theta, \delta$, and $\lambda$ respectively. See text for details.

phases are relatively robust with respect to a complex 3D structure, onset times can vary significantly. This can cause problems in locating and estimating faulting parameters.

\section{TELESEISMIC MODELING OF THE M7.9 DENALI FAULT EARTHQUAKE}

In view of the above problem, we performed this work in a progressive sense, i.e., starting the inversion with the simplest assumptions of fault geometry and Green's functions, and gradually improving it with additional information. For the convenience of the presentation, we label the results of different runs by phases. If additional complexities are warranted, the later phases should be better constrained than the earlier ones.

\section{FAST SOLUTION (PHASE I)}

We start with the Preliminary Determination of Epicenters (PDE) location $\left(63.74^{\circ} \mathrm{N},-147.69^{\circ} \mathrm{E}\right.$, origin time: $2002 / 11 / 03$ 22:12:40.7) provided by National Earthquake Information Center (NEIC) and the preliminary Harvard Centroid Moment Tensor solution (CMT, and see Table 1 and Figure 1). A rectangular plane along one of the best double- couple planes derived from this CMT solution is chosen as the fault plane (Table 2 and Figure 2). Even though there are two possible solutions, for a large unilateral strike-slip event such as the Denali fault earthquake, the real fault plane can be easily determined by simply comparing the centroid location with the PDE location. By definition, the latter is the position where rupture initiates and the former is the centroid of

Table 2. Fault planes used in different phases

\begin{tabular}{lcccc}
\hline \hline Phase & Plane A & Plane B & Plane C & Plane D \\
\hline Phase I & $\theta=298^{\circ}, \delta=86^{\circ}$ & N/A & N/A & N/A \\
Phase II & $\theta=268^{\circ}, \delta=70^{\circ}$ & $\theta=298^{\circ}, \delta=80^{\circ}$ & N/A & N/A \\
Phase III & $\theta=268^{\circ}, \delta=80^{\circ}$ & $\theta=221^{\circ}, \delta=35^{\circ}$ & $\theta=298^{\circ}, \delta=80^{\circ}$ & $\theta=320^{\circ}, \delta=90^{\circ}$ \\
\hline \hline
\end{tabular}



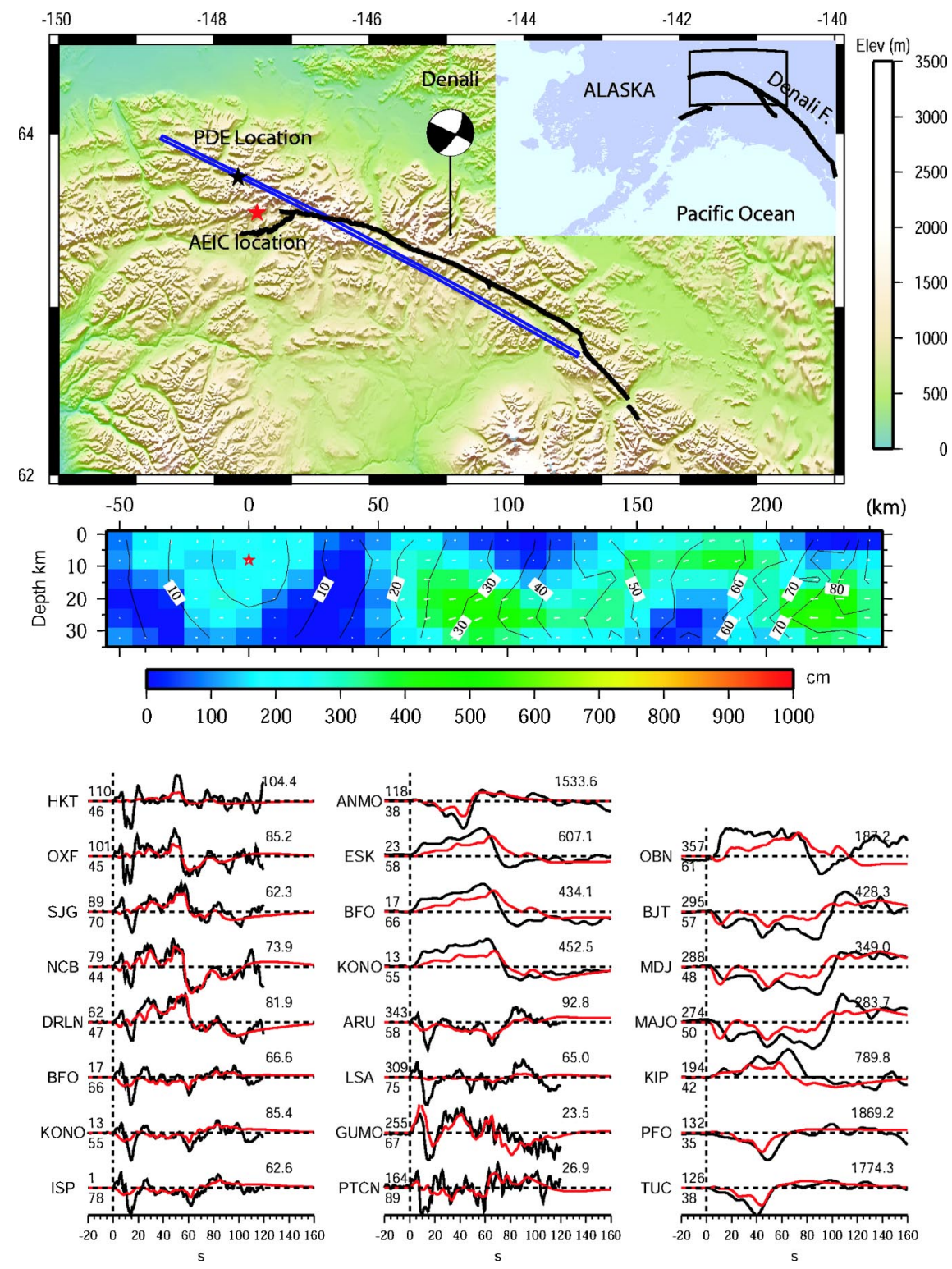

Figure 2. Fault geometry, slip distributions and waveform fits for the Phase I model. The top panel shows the surface projection of the Phase I fault model (box). The stars show the PDE and AEIC locations, and a focal mechanism shows the Harvard CMT solution for the Denali fault earthquake. There are discrepancies between the predicted fault geometry and the observed surface rupture trace (black lines, Eberhart-Phillips et al. 2003). The middle panel shows slip distribution looking from the northeast. The star indicates the hypocenter, the shades indicate the slip amplitude, and contours display the rupture initiation time. The bottom panel shows the waveform fits with data in black and synthetics in gray. The $\mathrm{P}$ waveforms were truncated by arrivals of the PP phase. The number at the end of each trace is the peak displacement of the data in micrometers, and is used to normalize both records and synthetics. The azimuth and distance in degrees are indicated at the beginning of each record with the azimuth on top. 
Table 3. Velocity structure of the Denali source region

\begin{tabular}{cccc}
\hline \hline $\mathrm{V}_{\mathrm{p}}(\mathrm{km} / \mathrm{s})$ & $\mathrm{V}_{\mathrm{s}}(\mathrm{km} / \mathrm{s})$ & $\rho\left(10^{3} \mathrm{~kg} / \mathrm{m}^{3}\right)$ & Thickness $(\mathrm{km})$ \\
\hline 6.0 & 3.5 & 2.7 & 11 \\
6.6 & 3.7 & 2.9 & 11 \\
7.2 & 4.0 & 3.1 & 12 \\
8.05 & 4.4 & 3.3 & Half-space \\
\hline \hline
\end{tabular}

Note: This velocity structure is interpolated from Crust2.0 (Laske et al. 2001) but without the ice layer.

the entire rupture. The centroid locations therefore should be closer to the real fault plane than the conjugate plane. In this case, the fault plane oriented NW satisfies this criterion (Figure 2, Table 1). For the more general case, we could reach this conclusion by comparing the waveform fits of finite inversions based on two nodal planes, or using the line source approaches suggested by Kikuchi and Kanamori (1991). We let this fault plane have a size of $300 \mathrm{~km}$ along strike, by $36 \mathrm{~km}$ down dip, and then divide it into 180 subfaults of dimension $10 \mathrm{~km}$ by $6 \mathrm{~km}$. The total number of unknowns is 720 by using a symmetric cosine slip-rate function approximation (e.g., Hartzell et al. 1996; Ji et al. 2002a). We assume that the rupture initiated at the PDE hypocenter.

Twelve teleseismic P waveforms and $11 \mathrm{SH}$ waveforms of the Denali fault earthquake were used in the Phase I analysis. These records were downloaded from the IRIS data center, and integrated to displacement. We did not try to remove their instrument responses except the gain factors because the deconvolution is unstable at low frequency. Thus the records can be treated as band-pass filtered ground displacements. The synthetic seismograms are convolved with these filters to be consistent with the data. Finally, during the inversion, we align the data using the $\mathrm{P}$ and $\mathrm{SH}$ arrival times predicted by the IASPEI-91 travel-time tables (Kennett and Engdahl 1991).

We use a 1D layered structure (Table 3) interpolated from the global Crust2.0 (Laske et al. 2001) to approximate the structure in the source region and treat the receiver sites as on a half-space. The inversion results are presented in Figure 2. We get reasonably good waveform fits to $\mathrm{SH}$ waves but we cannot reproduce the beginning portions of the $\mathrm{P}$ waves. All $\mathrm{P}$ waves show positive polarities, which suggests a thrust event occurred at the beginning of this rupture as shown in the slip distribution (Figure 2). However, the misfits suggest that a fault plane with different strike and dip angles needs to be considered. This result is consistent with the work of Kikuchi and Yamanaka (2002). The scalar summation of the seismic moment of each subfault is $6 \times 10^{20} \mathrm{Nm}$ using a rigidity model derived from the layered structure (Table 3), which is smaller than the Harvard CMT solution (Table 1). The inverted fault rupture is heterogeneous and includes at least three asperities. In addition to the thrust subevent near the hypocenter, there is a big " $U$ " shape asperity from $40 \mathrm{~km}$ to $200 \mathrm{~km}$ and another one at about $225 \mathrm{~km}$ (Figure 2). The asperity shape from $50 \mathrm{~km}$ to $250 \mathrm{~km}$ is very similar to the result of Kikuchi and Yamanaka (2002). The inverted average rupture velocity is $3.0 \mathrm{~km} / \mathrm{sec}$. 


\section{GEOLOGICAL INPUT AND LOCATION REFINEMENT (PHASE II)}

While the Phase I model can explain the teleseismic data fairly well, it should not be directly used to evaluate near-fault earthquake shaking because the fault plane differs significantly from the real location due to two errors. First, the PDE location $\left(63.74^{\circ} \mathrm{N},-147.69^{\circ} \mathrm{E}\right)$ is about $30 \mathrm{~km}$ northwest of a more accurate hypocenter $\left(63.5175^{\circ} \mathrm{N},-147.4444^{\circ} \mathrm{E}\right.$; origin time, $2002 / 11 / 03$ 22:12:41, gray star in Figure 2) located by the Alaska Earthquake Information Center (AEIC), which causes the entire slip region to shift northwestward. Consequently, the region of strong shaking is mislocated. Second, the Denali fault bends more than $20^{\circ}$ clockwise at about $-146^{\circ} \mathrm{E}$ longitude. Omitting such a curve may not greatly change the waveform fits to the long-period teleseismic body waves, but it will have serious effects on both slip modeling and strong-motion estimations. A curved fault is longer than a straight planar one. Because we map the seismograms into spatial-temporal variation of fault slip in the finite-fault inversions, a shorter fault length will create errors in both rupture velocity and slip amplitude. In addition, fault curvature will change the fault position and the local radiated pattern. Both of these factors strongly affect the strong motion at particular near-fault sites, such as in the 1999 Hector Mine earthquake (Ji et al. 2002b).

Accurate hypocenter location and fault geometry are two essential pre-conditions of finite fault inversions. Whereas earthquake location is a classic seismic problem and has not been fully solved, because large shallow earthquakes usually occur on mature faults that have been documented by geologists or from a high-resolution global digital elevation model (DEM) map, we are able to correct for fault geometry by taking advantage of this fact and combining it with any available aftershock pattern. Therefore, a "shifting and matching" process may help to reduce the uncertainty. Our Phase II model is a result of this process.

In this second generation of fault modeling (Figure 3), we use two fault planes to approximate the geometry of the Denali fault trace inferred from the global DEM map GTOPO30. The first plane has a strike of $268^{\circ}$, approximately along the western Denali fault strike. Because the previous Phase I modeling cannot explain the P-wave records in the first $20 \mathrm{sec}$, here we decrease the dip angle to $70^{\circ}$. In our experience, reducing the dip angle of a high-angle thrust fault could increase the amplitudes of teleseismic P waves. Thus, we intend to test whether the misfits are caused by an inaccurate dip angle. The second fault segment follows the east Denali fault with a strike of $300^{\circ}$ and a dip of $80^{\circ}$ to the northeast. The subfault size is the same as was used in the Phase I simulation. We let the rupture initiate at the more accurate AEIC location, and then performed the inversion again. In order to make the inversion more stable, we let the rupture propagate at the nearly constant velocity of $3.0 \mathrm{~km} / \mathrm{sec}$ found in the Phase I study.

The Phase II inversion results and waveform fits are shown in Figure 3. The overall waveform fits improve considerably over the earlier results, particularly for the SH waves. However, the mismatches for the beginning portions of the $\mathrm{P}$ waves are still obvious. A more detailed study needs to be considered for further improvement. The scalar seismic moment of this model is $8 \times 10^{20} \mathrm{Nm}$, larger than that of Phase I but consistent with the improved fit to the SH waveforms. 

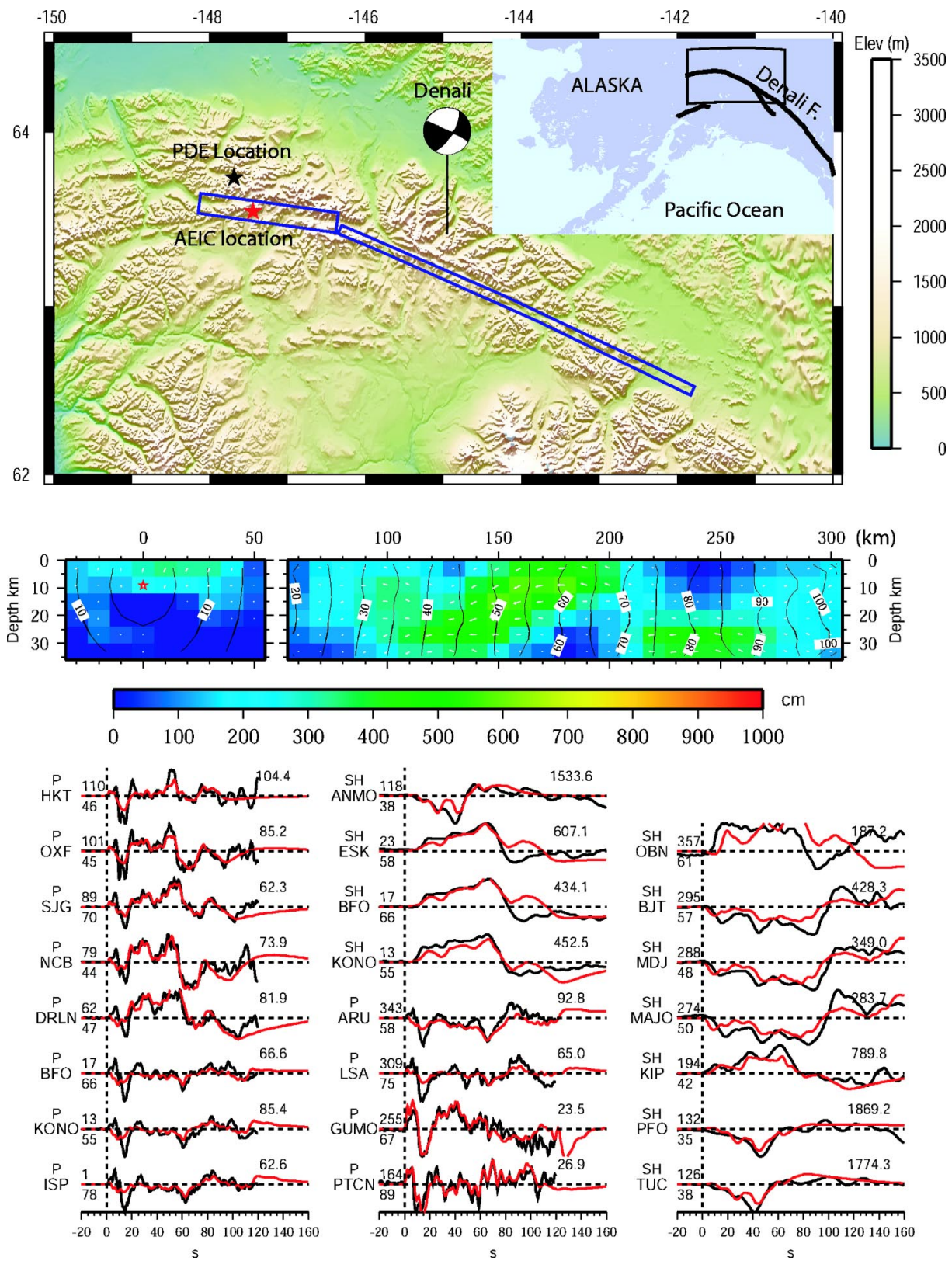

Figure 3. Fault geometry, slip distributions and waveform fits for the Phase II model. In the top panel, a black star shows the PDE location and a gray one indicates the AEIC location. The focal mechanism shows the Harvard CMT solution of the Denali fault earthquake. The boxes show the surface projection of the Phase II model. The middle panel shows the slip distribution. The star indicates the hypocenter, the shades indicate the slip amplitude, and contours display the rupture initiation time. The bottom panel shows the waveform fits with data in black and synthetics in gray. 

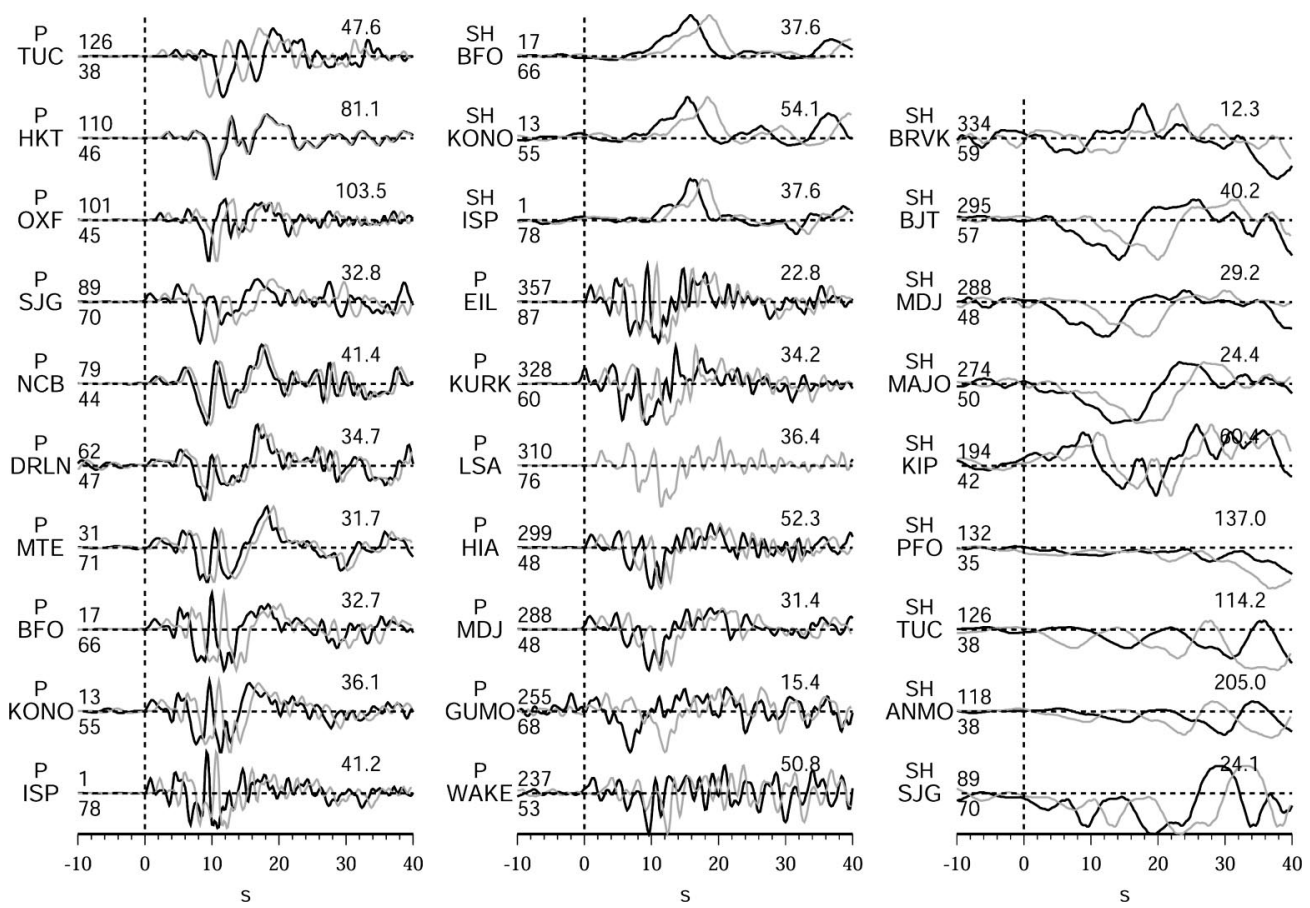

Figure 4. Comparison of the data before and after the time corrections. The black traces are aligned with body wave arrivals using the IASPEI-91 table. The gray traces show the same data but time-corrected relative to the Nenana Mountain event. Most paths are faster than the IASPEI-91. However, the ray paths along the eastern Pacific coast are slower in both $\mathrm{P}$ and SH as expected (e.g., stations PFO and TUC.)

\section{PATH CALIBRATION AND PHASE III}

Before refining the model of rupture when the P-waves are poorly fit, we will address another issue involving the alignment of synthetics with observations.

Synthetic waveforms generated by standard 1D earth models generally arrive a few seconds earlier or later than the observed P-wave, and somewhat more for S-waves. The usual approach is to align the beginning of synthetics manually with the initial break of data. This process works reasonably well when the rupture starts energetically, but is not that straight forward for large complex events where the S-wave onsets are difficult to determine. In Appendix A, we discuss a path calibration procedure based on modeling a nearby, impulsive event, the 2002 M6.7 Nenana Mountain earthquake.

In Figure 4, we show a comparison of the body waves of the Denali fault earthquake before and after correcting for travel time. To emphasize the difference, the ground velocity rather than displacement is presented. Apparently, the upper mantle velocity structure beneath the Denali hypocenter is generally faster than the AK135 layered model used in the IASEIP-91 travel-time table (Kennett and Engdahl 1991) except the path along the North American cordillera. Individual path effects are more complex. For in- 
stance, the SH path to station SJG is $5 \mathrm{sec}$ faster than the prediction using the IASPEI-91 tables, while the SH path to station TUC is $8 \mathrm{sec}$ later. Such large differences could not be determined by just inspecting the data, but correlate highly with the 3D tomography studies (e.g., Ritsema et al. 1999).

This approach also allows us to compare local and teleseismic observations. Many times, local stations record beginning motion that is too small to be seen teleseismically (nucleation phases, for example, Ellsworth and Beroza 1995). Thus, it becomes difficult to fix the epicenter locations used in teleseismic inversions. If we assume that the relative locations and origin times obtained by the same local array (AEIC) are correct for the two events, we could identify the lag between the earthquake initiation and the significant (teleseismic) motion. After applying this timing correction, we see a consistent pattern of about $2 \mathrm{sec}$ lag in the P-wave onsets. This can explain the difference between the focal mechanisms when determined locally or teleseismically. Because the residuals are apparently independent of the azimuth, the horizontal locations appear to be close.

We then inverted for a point source using $\mathrm{P}$ waveforms in the first $20 \mathrm{sec}$. The best double-couple solution (strike, $221^{\circ} / 55^{\circ}$; dip, $35^{\circ} / 50^{\circ}$; and rake, $82^{\circ} / 95^{\circ}$ ) is consistent with result of Kikuchi and Yamanaka (2002), which was $227^{\circ} / 40^{\circ}$ for the northwest dipping plane. In this model, we chose the northwest dipping plane for the Susitna Glacier fault, which was discovered after this earthquake.

With the above specifications, we built a more complex fault geometry with four fault planes. Planes A and C are still along the Denali fault, and both of them dip $80^{\circ}$ to the northeast. Two new fault planes were added. Plane B has a strike of $221^{\circ}$ and a dip of $35^{\circ}$ to the northwest. D is a vertical fault plane along the Totschunda fault. It has been active during Holocene time (Page et al. 1995), rather than the eastern branch of the Denali fault. There are some discrepancies between this predicted geometry and field observations, particularly for the Susitna Glacier fault (Eberhart-Phillips et al. 2003, and Figure 5). We let the rupture initiate on the west Denali fault, plane A, at the origin time of the AEIC. However, we let the rupture initiation of plane B occur at the same position, but we lag it by two sec. After that, both A and B can rupture simultaneously. Plane $\mathrm{C}$ and $\mathrm{D}$ intersect at $-143.4^{\circ} \mathrm{E}$ longitude. We also let the eastern portion of plane $\mathrm{C}$ rupture simultaneously with plane $\mathrm{D}$.

The results of this inversion are shown in Figure 5. Both P and SH waveforms can be explained well by this model. The thrust motion on plane B dominates the rupture of the first $10 \mathrm{sec}$ even though slip is permitted to occur on both plane A and B in the inversion. The significant shallow slip on plane A starts $25 \mathrm{~km}$ east of the hypocenter. Rupture then propagates eastward along the Denali fault before stopping sharply about $220 \mathrm{~km}$ east of hypocenter. The rupture then jumps to the Totschunda fault but the surface rupture dies out quickly. The peak slip is as high as $9 \mathrm{~m}$. Such a rupture scenario is generally consistent with the results from both strong-motion and geodetic observations (Dreger et al. 2002, Frankel et al. 2002, Hreinsdottir et al. 2003). The average rupture velocity is still $3.0 \mathrm{~km} / \mathrm{sec}$, but the velocity appears to be slower than the average during the rupture of the first $100 \mathrm{~km}$ and then accelerates significantly (see initiation contours in Figure 4), consistent with the strong-motion in version result (Eberhart-Phillips et al. 2003, Frankel et al. 2002). 

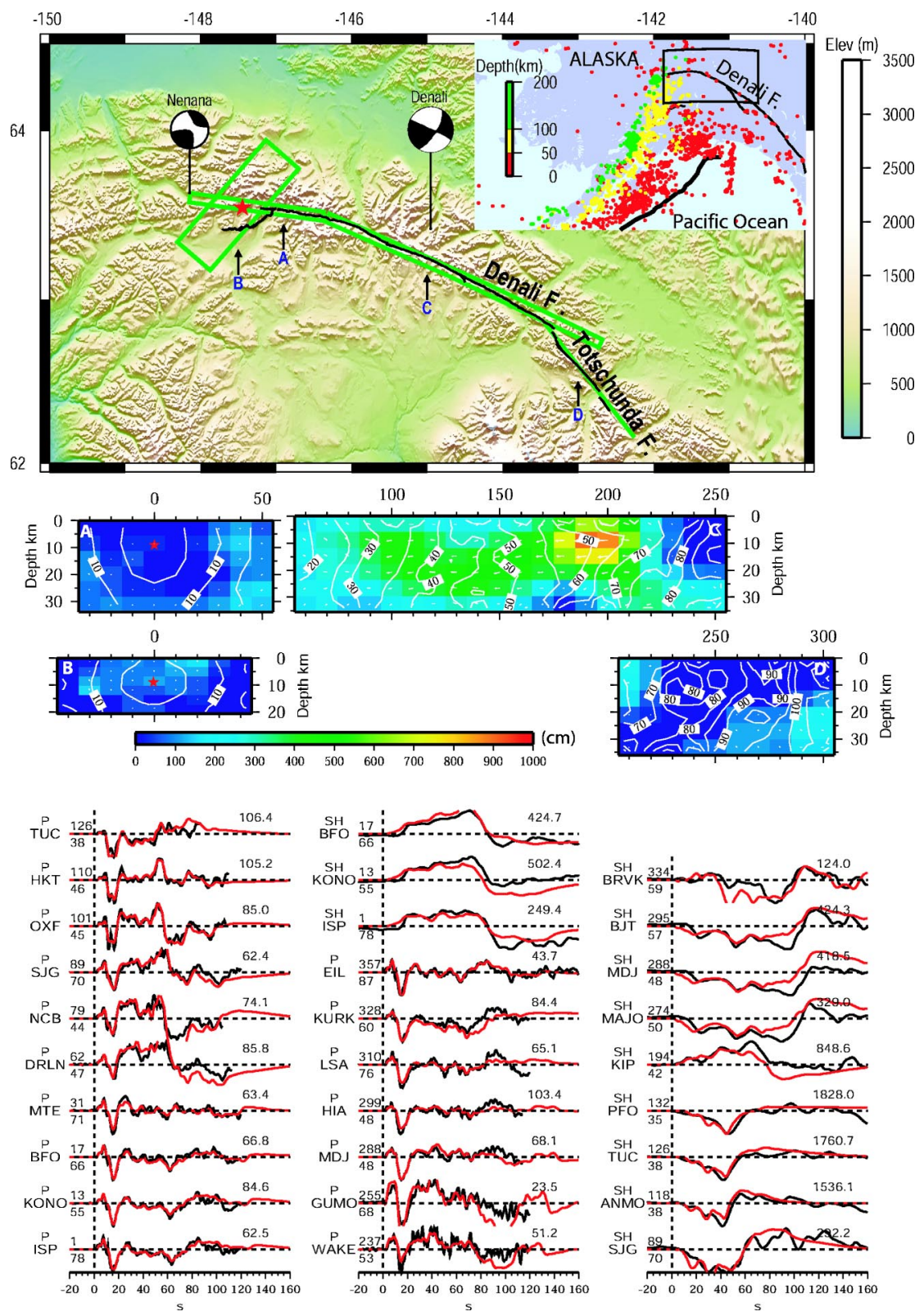

Figure 5. Fault geometry, slip distribution, and waveform fits for Phase III modeling. In the upper panel, a gray star shows the AEIC hypocenter of the Denali fault earthquake and two focal mechanisms show the Harvard CMT solutions of the Denali fault and Nenana Mountain earthquakes. The black lines show the surface rupture traces (Eberhart-Phillips et al. 2003). The boxes show the surface projection of the Phase III model. The middle panel shows slip distribution. The star indicates the hypocenter, the shades show the slip amplitude, and contours display the rupture initiation time. The bottom panel shows the waveform fits with data in black and synthetics in gray. The data were aligned by the corrected P or SH first arrivals. 
The scalar summation of the total seismic moment is $1.1 \times 10^{21} \mathrm{Nm}$, over 40 percent larger than the result of the Harvard CMT $\left(7.5 \times 10^{20} \mathrm{Nm}\right.$, and Table 1). However, we found that such a discrepancy is, in fact, reasonable by considering two differences between our approach and the CMT. By definition, the CMT represents the tensor rather than scalar summation of the entire rupture process. In addition, the Harvard CMT uses the rigidity derived from the PREM model (Dziewonski and Anderson 1981) at the centroid depth instead of the more realistic depth-dependent rigidity model used in our study. For a direct comparison we performed the same calculation as that of the CMT. Numerical tests shown in Table 1 support our suspicion. The seismic moment of the Phase III model drops to $9.2 \times 10^{20} \mathrm{Nm}$ after tensor summation, and further reduces to $8.1 \times 10^{20} \mathrm{Nm}$ when using the same rigidity as the Harvard CMT. Differing seismic moment estimates from moment tensor inversions versus finite-fault inversion results have also been reported in the studies of several other large earthquakes (e.g., the 1992 Landers earthquake, Wald and Heaton 1994).

\section{DISCUSSION}

In the previous sections we outlined the steps taken in progressively upgrading the modeling of teleseismic data by adding local information pertaining to the tectonic setting. Here we discuss predictions based on these models and comparisons with independently observed data in terms of both the static and dynamic fields.

\section{STATIC PREDICTIONS}

A team of geologists went to the field a day after the Denali fault earthquake and collected surface offsets in a two-week investigation (Eberhart-Phillips et al. 2003). While theoretically the surface slip inverted from teleseismic data should be consistent with the co-seismic surface offsets, a real comparison bears many uncertainties. The geological measurements usually include afterslip and can show considerable scatter among adjacent measurements due to structural complications. The largest values are considered closest to the actual slip distribution (Peter Haeussler, personal communication). On the other hand, because each subfault has a size of $10 \mathrm{~km}$ along strike by $6 \mathrm{~km}$ down dip, the inverted slip amplitude reflects the average value within a spatial window of $60 \mathrm{~km}^{2}$. The smoothing constraint that we implement further averages the slip in the adjacent subfaults (Ji et al. 2002a). Considering these limitations, we are surprised by the comparison showed in Figure 6, where the slip of the top subfaults is plotted, along with surface slip measurements. The surface slip of the Denali fault earthquake increases gradually from west to east before sharply ending near $-143.2^{\circ} \mathrm{E}$ longitude. The Phase III model matches this pattern very well. Both the location and shape of the peak at the eastern end are well preserved though the model values are smaller than the field observations. In fact, even the Phase II model matches the general pattern but with a smaller overall amplitude. Therefore, the general fault offset pattern can be recovered with the teleseismic inversion alone. Smaller subfault dimensions, while adding to the inversion computationally, may improve recovery of the surface offset.

From the field survey (Figure 6) and the aftershock distribution (Eberhart-Phillips et al. 2003), the Denali rupture stops on the Denali fault at about $220 \mathrm{~km}$ and transfers to the Totschunda fault. This feature is not recovered in the Phase I model, which has a 


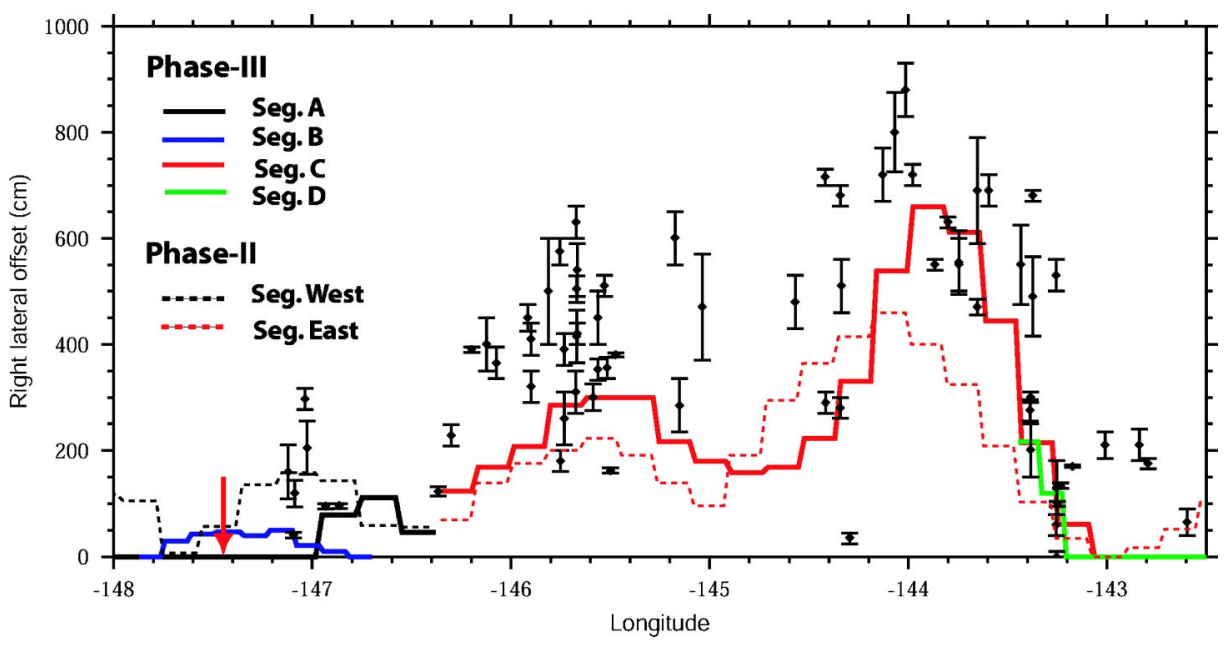

Figure 6. Comparison of surface offset measurements (black dots with error bars) and inverted results (shaded lines) from Phase II and III. The hypocenter is indicated with a gray arrow.

deep asperity from $210 \mathrm{~km}$ to $250 \mathrm{~km}$, with a peak slip of 5 meters, and rupturing during the period of 70 to $80 \mathrm{sec}$ (Figure 6). However, both the shape and size of this asperity change with additional corrections. Adding the fault geometry correction and using the AEIC hypocenter makes it deeper and smaller in the Phase II model. Correcting the onset times further reduces its peak slip amplitude to only about 2 meters in the Phase III model. Because there is little seismic energy released during the time period $70 \mathrm{sec}$ to 90 sec on fault segment D (Figure 5), adding the Totschunda fault branch in Phase III is apparently not the cause of such changes. Thus, we conclude that this asperity may be an inversion artifact caused by inaccurate alignment of seismic signals. Finally, both Phase II and III models have another asperity from 260 to $300 \mathrm{~km}$ and rupturing during 90 to $100 \mathrm{sec}$. This is associated with a coherent $\mathrm{P}$ phase, e.g., the negative pulse starting around $80 \mathrm{sec}$ at station SJG (Figure 5). However, because its size also decreases in Phase III, whether it is real or not will require additional analysis with near-source observations.

The static predictions are presented in Figure 7 for the available GPS measurements (Hreinsdottir et al. 2003). The predictions from Phase II and III reproduce the observations fairly well. Phase I is simply not able to explain the station to the left of the AEIC location. Adding the thrust plane (plane B in Figure 5) resolves this disparity. However, the model fails to match two close fault measurements, which indicates more accurate fault geometry is required. The complete static field is plotted in Figure 7 (right), where the large strike-slip component dominates the horizontal offsets. The vertical field is controlled mostly by the dip-slip displacements. It is small in amplitude and therefore more difficult to predict. After comparing with the field observations (Eberhart-Phillips et al. 2003), our vertical prediction is consistent with observations around $-144.5^{\circ} \mathrm{E}$ where the biggest asperity is located, but inconsistent with the relative small pattern around $-146^{\circ} \mathrm{E}$. 

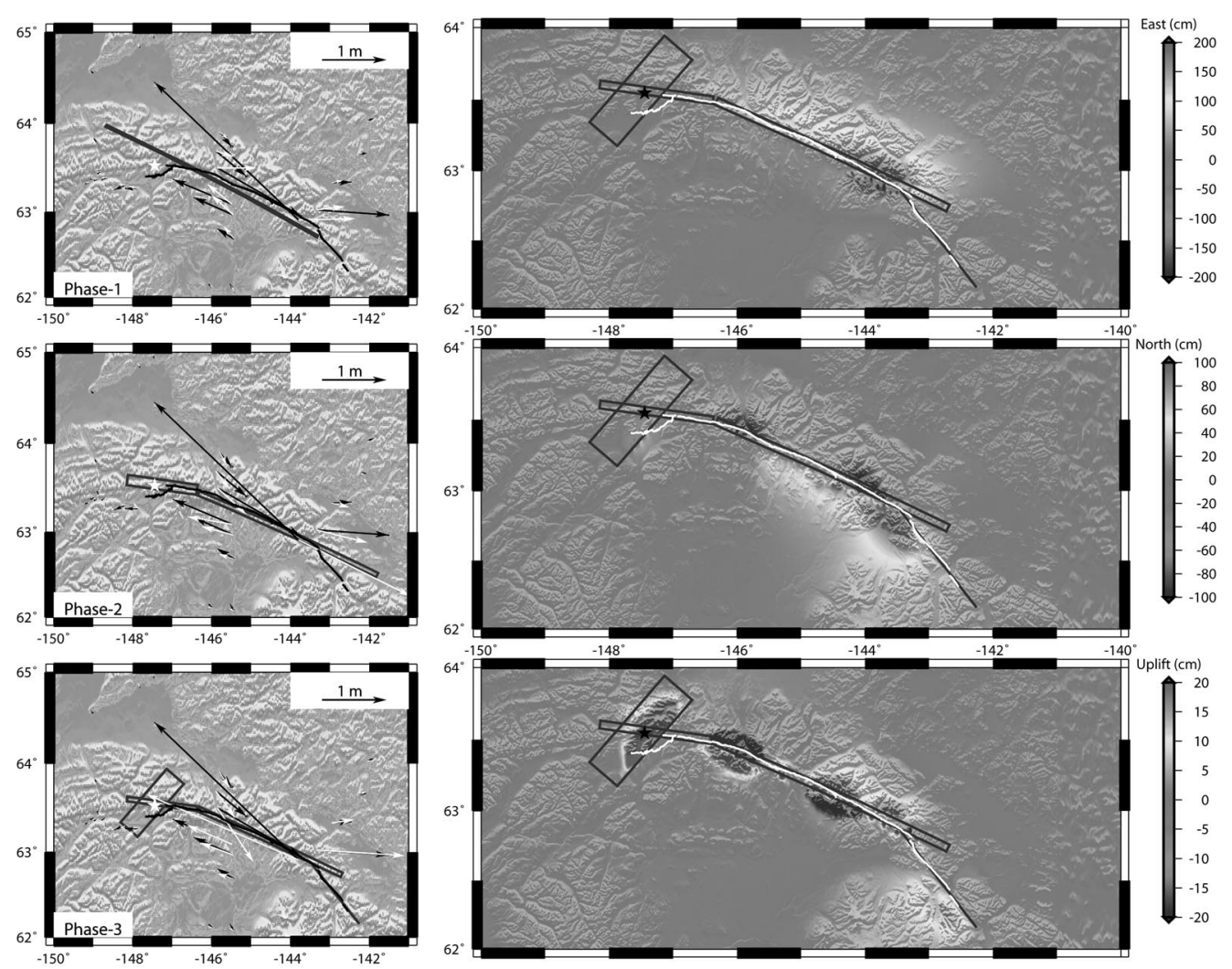

Figure 7. Prediction of the near-fault static field. Left: Comparison of horizontal GPS measurements (black arrows) and synthetic predictions (white arrows). The scale of vectors is indicated in the upper right corner. The boxes indicate the surface projections of fault planes. Black lines show the surface rupture trace (Eberhart-Phillips et al. 2003). The white star is the AEIC hypocenter. There are some discrepancies between the observed surface fault traces and predicted fault traces based on the DEM map. Right: Three component surface deformation fields predicted by the Phase III model. The white lines indicate the surface rupture trace.

\section{PREDICTION OF STRONG-MOTION PARAMETERS}

The above comparison demonstrates the ability of teleseismic inversion in producing an evaluation of the possible static offsets. However, the local strong-motion parameters such as peak ground velocity (PGV) and intensity (for example, instrumental intensity) are sensitive to local velocity structure and are, therefore, more difficult to predict. Even though ideally we would use a 3D local velocity structure in the strong-motion simulation, such a structure is not available in most situations, nor is it practical to make such computations for a rapid ground-motion estimation. Here we use the 1D layered structure interpolated from the global Crust2.0 (Laske et al. 2001). Because of the many simplifications used in our simulations, we only intend to predict the long-period ground 
motion. The Green's functions were therefore low-pass filtered at $0.5 \mathrm{~Hz}$. For such a large earthquake, PGV values will likely be dominated by the long-period energy we retain.

Another effect that we need to address is the finiteness of the subfaults. Numerically, we approximate the seismic response of a subfault by summing the Green's functions of point sources uniformly distributed on the subfault surface and individually lagged for the rupture propagation. For these inversions, subfaults are sampled as point sources on a grid spacing of $1.5 \mathrm{~km}$. Because the apparent velocity of the teleseismic body wave is high, such a coarse grid is sufficient to model the 2-sec seismic signals. However, it may be too coarse to simulate the near-fault strong motion. For this reason, we tested a smaller grid size of $0.5 \mathrm{~km}$ as well. We found that while there are some differences between the results of these two grids, they are not serious. For stations tens of kilometers away from the fault, synthetic seismograms generated with the coarse grid tend to have larger high-frequency surface waves. The PGV estimations will also be higher. This is consistent with the smaller apparent velocity of the surface waves. Fortunately, the relative differences are less than a factor of two. On the other hand, for stations close to the fault trace or even right above the fault plane, the coarse grid tends to underestimate the PGV. If we consider sites greater than $1.5 \mathrm{~km}$ from the fault trace, the relative differences are limited to 20 percent. Because reducing the grid size will significantly increase the computational cost (particularly in the forward strong-motion estimation), the coarse grid is more favorable in real-time estimation and is used in this study.

With the slip model and Green's functions, we generate the strong motion using a $10-\mathrm{km}$ by $10-\mathrm{km}$ grid within the near-source region, shown in Figure 8 . The predicted peak ground velocity $(P G V)$ is related to instrumental intensity $(\mathrm{Im})$ using the empirical relationship developed by Wald et al. (1999a, b):

$$
\operatorname{Im}=2.35+3.47 \log _{10}(P G V)
$$

One known limitation of this relationship for our purpose is that it was derived for moderate-sized (M6.0-M7.2) strike-slip events in California. For the Denali fault event, we expect that $P G V$ has longer-period content than the events used in the derivation of Im. The complex relationship between the potential frequency-dependence of the above equation, our band-limited predictions, and the actual intensity has yet to be established.

Both the Phase II and III models are used to generate what we refer to as a numerical, predictive ShakeMap. The 2-sec peak ground velocity could be as high as $3 \mathrm{~m} / \mathrm{sec}$ at the eastern end of the Denali fault rupture and at the thrust fault at the western end. The former one shows a much broader region and is due to the combined effects of high on-fault slip velocity and strong directivity caused by the relatively high rupture velocity (see the rupture-time contours in Figure 5). This result might be contaminated by several factors, such as the unreliable slip east of the intersection of the Denali and Totschunda faults. The high- $P G V$ region caused by the thrust motion is mislocated because of the mismatch with the fault geometry of the Susitna Glacier fault (Figure 5). The transAlaska pipeline crosses the Denali fault in a valley indicated by a white arrow in Figure 8. This valley is, in fact, right on the western boundary of the high- $P G V$ region with 2 $\mathrm{m} / \mathrm{sec}$ in the simulation of both Phase II and III models. The predicted $P G V$ value at the 

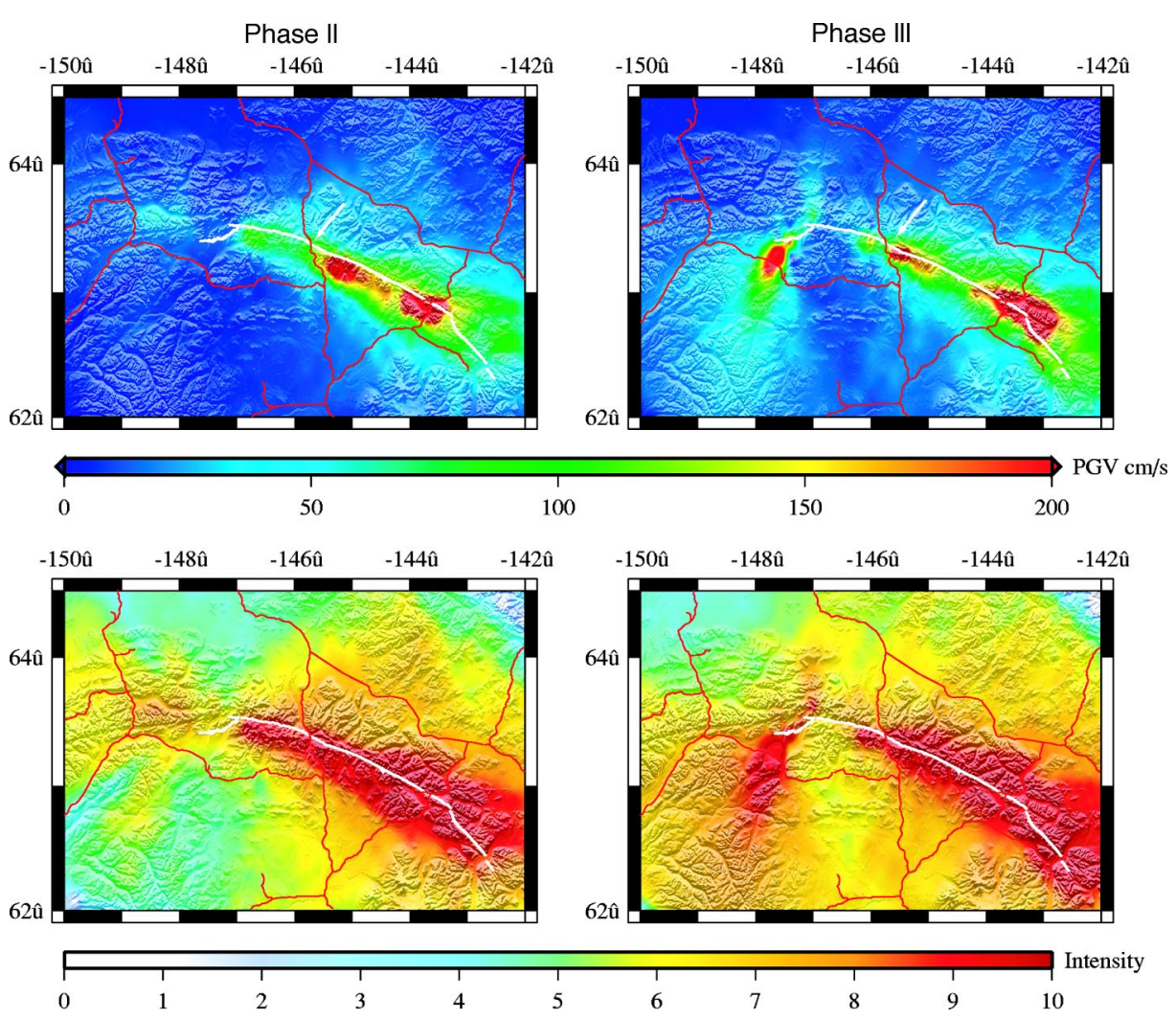

Figure 8. Peak ground velocity and instrumental intensity maps (Wald et al. 1999a) predicted from the Phase II and III models. The image is interpolated from forward prediction values at a grid spacing of $10 \mathrm{~km}$. The prediction of the Phase II model shifts away from the Denali fault trace because of the inaccurate location of the fault plane (Figure 2). The surface offset traces are plotted in white and highways in gray. The trans-Alaska pipeline goes through the valley indicated by a white arrow.

pipeline's Pump Station 10 is $1 \mathrm{~m} / \mathrm{sec}$, about 33\% smaller than the recorded value $(1.5$ $\mathrm{m} / \mathrm{sec}$ ). Another encouraging observation is that the result of the Phase II model is similar to the result of Phase III east of $-147^{\circ} \mathrm{E}$ longitude. Hence, even though this estimation still awaits evaluation with further information, we could conclude that at least the results are self-consistent and that the more rapidly determined Phase II results show promise.

The comparison also highlights the importance of more detailed geological information. For instance, if we had known the details of the Susitna Glacier fault earlier, we might have been able to obtain Phase III results earlier. 


\section{CONCLUSIONS}

We used the wavelet inversion procedure developed by Ji et al. (2002a) to obtain estimates of possible rupture characteristics of the 2002 M7.9 Denali fault earthquake. Three fault models are presented to illustrate the incremental improvements in matching the teleseismic waveform data with the addition of various fault segments and timing corrections. We used a smaller well-located foreshock to calibrate absolute travel times at a selected number of stations recording both events, and by using the global DEM map and geological information to construct a reasonable fault geometry. While we would prefer to have more static control in these efforts, we can still produce useful results. Our preferred model has four fault planes with a total seismic moment of $10^{21} \mathrm{Nm}$. The earthquake initiated as a thrust event but most of the seismic moment was released by a U-shaped strike-slip asperity distributed from $50 \mathrm{~km}$ to $220 \mathrm{~km}$ southeast of the hypocenter. The slip reaches its peak amplitude at the southeast end of the rupture and is as high as $9 \mathrm{~m}$. The rupture then jumps to the Totschunda fault.

We conclude that:

1. The finite fault inversion using teleseismic data can capture the overall slip pattern of this complex large earthquake even with the simplest assumptions.

2. Adjusting the fault geometry given by the CMT solutions with a global DEM map is a useful approach for the analysis of large, shallow earthquakes.

3. The 3D earth structure strongly perturbs the onset time of teleseismic body waves and therefore seriously affects the resulting slip model. Fortunately, we can correct for such timing variations by using a well-recorded, nearby foreshock or aftershock. Ignoring such timing errors can cause problems.

4. The static field and fault offsets are predicted with the inverted slip model. They appear to be in general agreement with the observations.

5. The strong ground motion parameters, $P G V$ and instrumental intensity, are also predicted. There are three high- $P G V$ regions located. The strongest ground shaking appears at the southeast end of the Denali rupture. The second strongest is associated with the thrust event on the Susitna Glacier fault. The third is on the east side of the trans-Alaska pipeline.

Although this example is encouraging, to gauge more fully how well this procedure works requires the analysis of many more large earthquakes. The tools and procedures described herein provide the basic foundation for an automated teleseismically-based inverse source inversion, coupled with forward ground-motion estimates. Such a system, now under development, will be able to provide estimates of the potential impact of major earthquakes worldwide more rapidly than is currently available.

\section{ACKNOWLEDGMENTS}

We thank Kerry Sieh and Sigun Hreinsdottir for the surface offset data and GPS data. Peter Haeussler and an anonymous reviewer provided constructive suggestions for the manuscript. The digital seismograms used in our inversion were downloaded from the IRIS data center. The figures were prepared by the GMT software (Generic Mapping Tools) written by Paul Wessel and Walter H.F. Smith. The research was supported by 
U.S. Geological Survey grant No. 03HQAG009. This is Contribution No. 8941, Division of Geological and Planetary Sciences, California Institute of Technology, Pasadena, California 91125.

\section{APPENDIX A: SLIP DISTRIBUTION OF THE 2002 M6.7 NENANA, ALASKA, EARTHQUAKE AND METHODOLOGY OF PATH CALIBRATION}

Compared to the M7.9 Denali fault earthquake, the 2002 M6.7 Nenana Mountain earthquake is smaller and more simple. The AEIC focal mechanism based on first motions is the same as that derived from the Harvard CMT solution. According to these solutions, the event occurred on a vertical fault plane striking N262 ${ }^{\circ} \mathrm{E}$. As in the Phase I model of the Denali fault earthquake, we first choose the fault plane, constructing a planar fault plane $48 \mathrm{~km}$ along strike and $20 \mathrm{~km}$ down dip, and further divide it into 60 subfaults each with a dimension of $4 \mathrm{~km}$ by $4 \mathrm{~km}$. We use a hypocentral depth of $10 \mathrm{~km}$.

As we did for the Denali fault earthquake, we downloaded the teleseismic P and SH waveforms from the IRIS dataset and converted them into filtered displacements. Some of the teleseismic records have clear beginning phases so that we could hand-pick their arrivals. We inverted the slip distribution in an iterative way. First we invert a preliminary model based on the hand-picked data only. Secondly, we use it to forward predict $\mathrm{P}$ and SH responses at other stations whose arrivals are not clear; and then correct the arrivals of those records by the cross-correlation of the data and the synthetic responses. Thirdly, the records aligned with corrected arrivals are added into the inversions to improve the slip models. The second and third procedures are repeated until the values of the arrivals became stable. The waveform comparison is shown in Figure A1 and the slip model is displayed in Figure A2. The result confirms that this event is relatively simple. Its peak slip is $2 \mathrm{~m}$ and the total seismic moment is $1.4 \times 10^{19} \mathrm{Nm}$.

The waveform fits shown in Figure A1 are not particularly good, for instance, the second peak of the SH record at BRVK and AAK. It may suggest some fault complexities other than the assumed planar character. However these effects do not seem to dominate the records. Using this model we could estimate the timing corrections relative to the 1D travel-time table, such as IASPEI- 91. To achieve this, we first align the data with arrival times predicted by the IASPEI-91 travel-time table for the AEIC hypocenter location and origin time. We use the inverted slip model of the M6.7 Nenana Mountain earthquake to predict the seismic waveforms of all available teleseismic stations, and shift the data until the synthetics fit the records best in a least square sense. These time shifts are mainly caused by the difference between the real (3D) earth and the AK135 layered model used in the IASEIP-91 travel-time table (Kennett and Engdahl 1991), and may be slightly contaminated by the possible fault complexities alluded to above. The locations of the Denali fault earthquake and Nenana Mountain earthquake are so close that it should be safe to assume that these shifts are also suitable for the records of the Denali fault earthquake. This procedure does not depend on the absolute location accuracy of the local network. Instead, we assume that the locations and origin times of the two events have embedded similar uncertainties. 

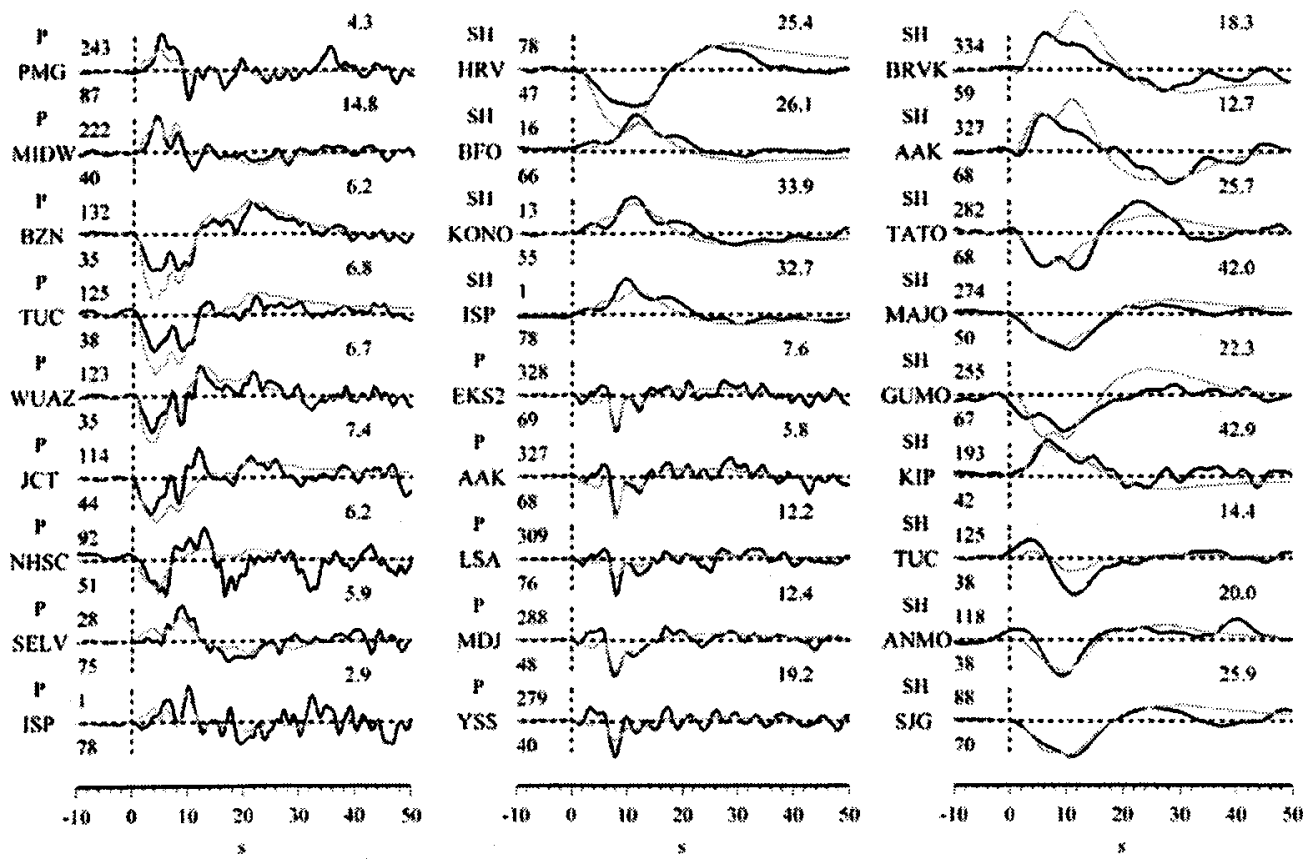

Figure A1. Comparison of synthetic seismograms (gray traces) and teleseismic P and SH waves (black) for the Nenana Mountain earthquake. The peak amplitudes of the data are indicated at the end of each trace and are used to normalize both data and synthetic seismograms. The numbers at the beginning of each trace are station azimuths (above) and epicenter distances (below).

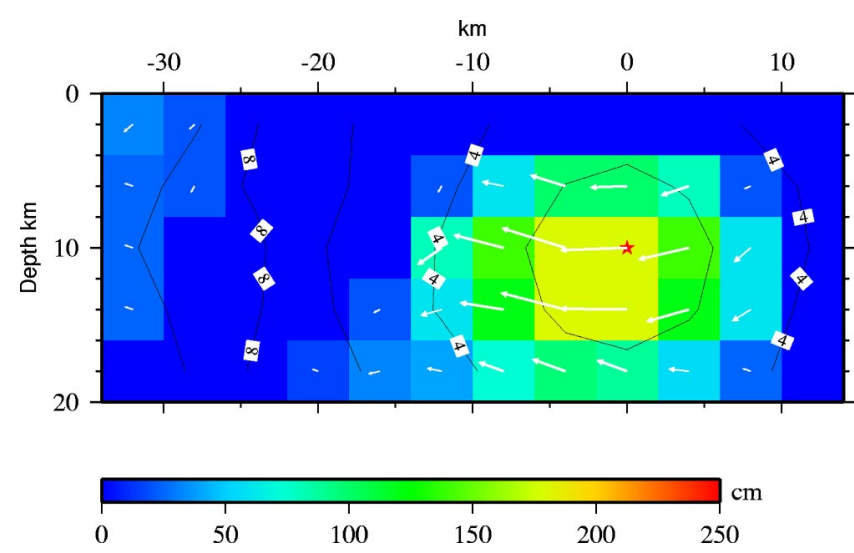

Figure A2. The slip distribution of the 2002 Nenana Mountain earthquake with the epicenter plotted as a gray star. 


\section{REFERENCES}

Demets, C., Gordon, R. G., Argus, D. F., and Stein, S., 1994. Effect of recent revisions to the geomagnetic reversal time-scale on estimates of current plate motions, Geophys. Res. Lett. 21 (20), 2191-2194.

Dreger, D., and Kaverina, A., 2000. Seismic remote sensing for the earthquake source process and near-source strong shaking: A case study of the October 16, 1999, Hector Mine earthquake, Geophys. Res. Lett. 27 (13), 1941-1944.

Dreger, D., Oblesby, D., Chi, W. C., Murray, M. H., Kore, K., Ratchkovski, N., and Hansen, R., 2002. Source kinematics and dynamics of the 3 November, $2002 \mathrm{Mw} 7.9$ Denali fault, Alaska earthquake, EOS Trans. Am. Geophys. Union 83, S72F-1343.

Dziewonski, A. M., and Anderson, D. L., 1981. Preliminary reference earth model, Physics of the Earth and Planetary Interiors 25 (4), 297-356.

Eberhart-Phillips, D., Haeussler, P. J., Freymueller, J. T., Frankel, A. D., Rubin, C. M., Craw, P., Ratchkovski, N. A., Anderson, G., Carver, G. A., Crone, A. J., Dawson, T. E., Fletcher, H., Hansen, R., Harp, E. L., Harris, R. A., Hill, D. P., Hreinsdóttir, S., Jibson, R. W., Jones, L. M., Kayen, R., Keefer, D. K., Larsen, C. F., Moran, S. C., Personius, S. F., Plafker, G., Sherrod, B., Sieh, K., Sitar, N., and Wallace, W. K., 2003. The 2002 Denali fault earthquake, Alaska: A large magnitude, slip-partitioned event, Science 300, 1113-1118.

Ellsworth, W. L., and Beroza, G. C., 1995. Seismic evidence for an earthquake nucleation phase, Science 268 (5212), 851-855.

Engdahl, E. R., van der Hilst, R., and Buland, R., 1998. Global teleseismic earthquake relocation with improved travel times and procedures for depth determination, Bull. Seismol. Soc. Am. 88 (3), 722-743.

Fletcher, H. J., and Freymueller, J. T., 1999. New GPS constraints on the motion of the Yakutat block, Geophys. Res. Lett. 26 (19), 3029-3032.

Frankel, A., Biswas, N. N., Martitosyan, A. H., Dutta, U., and McNamara, D. E., 2002. Rupture process of the M7.9 Denali fault, Alaska, earthquake determined from strong-motion recordings, EOS Trans. Am. Geophys. Union S72F-1340.

Hartzell, S., Liu, P. C., and Mendoza, C., 1996. The 1994 Northridge, California, earthquake: investigation of rupture velocity, rise time, and high-frequency radiation, J. Geophys. Res., [Solid Earth] 101 (B9), 20091-20108.

Hartzell, S. H., and Heaton, T. H., 1983. Inversion of strong ground motion and teleseismic waveform data for the fault rupture history of the 1979 Imperial Valley, California, earthquake, Bull. Seismol. Soc. Am. 73 (6), 1553-1583.

Hreinsdottir, S., Freymueller, J. T., and Fletcher, H. J., 2003. Coseismic slip distribution of the 2002 Mw7.9 Denali fault earthquake, Alaska, determined from GPS measurements, submitted to Geophys. Res. Lett.

Ji, C., Wald, D. J. and Helmberger, D. V., 2002a. Source description of the 1999 Hector Mine, California, earthquake, part I: wavelet domain inversion theory and resolution analysis, Bull. Seismol. Soc. Am. 92 (4), 1192-1207.

Ji, C., Wald, D. J. and Helmberger, D. V., 2002b. Source description of the 1999 Hector Mine, California, earthquake, part II: complexity of slip history, Bull. Seismol. Soc. Am. 92 (4), 1208-1226.

Kennett, B. L. N. and Engdahl, E. R., 1991. Travel times for global earthquake location and phase identification, Geophys. J. Int. 105 (2), 429-465. 
Kikuchi, M. and Kanamori, H., 1991. Inversion of complex body waves, Bull. Seismol. Soc. Am. 81 (6), 2335-2350.

Kikuchi and Yamanaka, 2002. http://wwweic.eri.u-tokyo.ac.jp/EIC/EIC_News/021103ALe.html

Lahr, J. C. and Plafker, G., 1980. Holocene Pacific North-American plate interaction in southern Alaska - implications for the Yakataga seismic gap, Geology 8 (10), 483-486.

Laske et al., 2001. http://mahi.ucsd.edu/Gabi/rem.html

Page, R. A., Plafker, G., and Pulpan, H., 1995. Block rotation in east-central Alaska-a framework for evaluating earthquake potential, Geology 23 (7), 629-632.

Ritsema, J., van Heijst, H. J., and Woodhouse, J. H., 1999. Complex shear-wave velocity structure imaged beneath Africa and Iceland, Science 286 (5446), 1925-1928.

Wald, D. J., and Heaton, T. H., 1994. Spatial and temporal distribution of slip for the 1992 Landers, California, earthquake, Bull. Seismol. Soc. Am. 84 (3), 668-691.

Wald, D. J., Quitoriano, V., Heaton, T. H., Kanamori, H., Scrivner, C. W., and Worden, C. B., 1999a. TriNet "ShakeMaps:" rapid generation of instrumental ground-motion and intensity maps for earthquakes in southern California, Earthquake Spectra 15, 537-555.

Wald, D. J., Quitoriano, V., Heaton, T. H., and Kanamori, H., 1999b. Relationship between peak ground acceleration, peak ground velocity, and modified Mercalli intensity for earthquakes in California, Earthquake Spectra 15, 557-564.

(Received 18 August 2003; accepted 27 January 2004) 